\title{
SYNTHESIS OF 8-METHOXYQUINOLINE-5-AMINO ACETIC ACID AND ITS HERBICIDAL POTENTIAL
}

\author{
Adewole E. ${ }^{1^{*}}$, Oke, O.T ${ }^{2}$ and Ojo $\mathrm{A}^{3}$ \\ ${ }^{* 1,3}$ Department of Chemical Sciences, Afe Babalola University, Ado-Ekiti, Nigeria \\ ${ }^{2}$ Department of Chemistry, Federal University of Technology, Akure, Nigeria.
}

*Corresponding Authors: -

Email.com: adewolen50@yahoo.com

\begin{abstract}
: -
The quinoline skeleton is often used for the design of many synthetic compounds with diverse pharmacological properties. 8-Methoxyquinoline 5-amino acetic acid was synthesized from coupling of monochloroacetic acid with 5-amino-8methoxyquinoline. The IR showed-OH stretch absorption and amino group (-NH) which is not too prominent at $3450 \mathrm{~cm}$ ${ }^{1}$ and $3300 \mathrm{~cm}^{-1}$, carbonyl $(C=O)$ absorption depicts at $1614 \mathrm{~cm}^{-1}$. The herbicidal activity of the synthesized compound was tested on the weeds and after 11 days of application, the weeds have dried completely indicating the efficacy of the compound.
\end{abstract}

Keywords: synthesis, 8-Methoxyquinoline 5-acetic acid, IR and herbicidal activity.

\section{(c) $\$(1)$}




\section{INTRODUCTION}

Herbicides are chemicals used with the intention of killing plants (Andrew et al 2011), chemical herbicides have replaced large number of farm labourers and boosted crop production. (Cindy, 1987), the chemicals are called weed killers; some of these weed killers act by interfering with the growth of the weed (Quastel 1950). Many compounds have been synthesized and have been found effective as weed control (Owolabi and Olarinoye (2008). The major aim of this research work was to synthesize 8-methoxyquinoline-5-amino acetic acid and test the compound for its herbicidal potential.

\section{Methodology}

Materials and methods:

8-Hydroxyquinoline was obtained from the chemical store of Chemistry Department, Federal University of technology, Akure, Nigeria. The sample appears as a pale light yellow crystalline compound.

\section{Preparation of 8-methoxyquinoline}

The principle of Norman (1993) guided the synthesis of the compound. To a solution of 8hydroxyquinoline $(1.05 \mathrm{~g}, 7.23 \mathrm{mmol})$ in acetone $(15 \mathrm{~mL})$ was added solid potassium carbonate $(1.0 \mathrm{~g}, 7.24 \mathrm{mmol})$ and methyl iodide $(0.45 \mathrm{ml}, 7.23 \mathrm{mmol})$.The reaction mixture was reflux for 24 hours.It was allowed to cool to room temperature and followed by filtration and removal of the solvent in vacuo. Flash chromatography (acetone) of the residue afforded the product $(815 \mathrm{mg}, 71 \%)$ as a light oil with retardation factor ( 0.58$)$ using (benzene/hexane 2:1
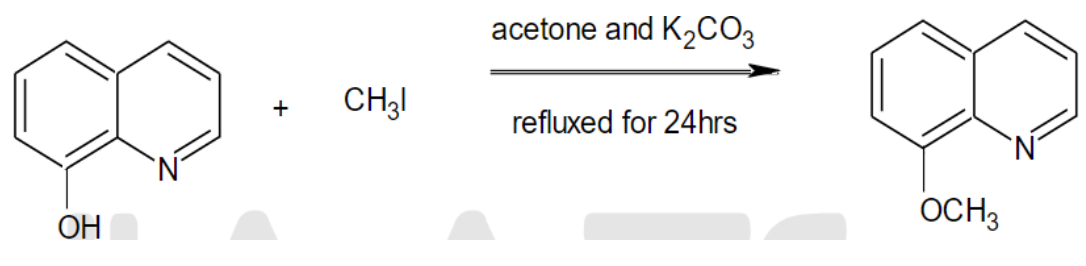

\section{Preparation of 5-Nitro-8-Methoxyquinoline}

The method of Norman (1993) was adopted. $5 \mathrm{~cm}^{3}$ concentrated sulphuric acid and $4 \mathrm{~cm}^{3}$ concentrated nitric acid were mixed with cooling. To the mixture in the cold,50mg of 8 methoxquinoline was added with shaking to dissolve. The reaction reached completion about 10-15 minutes due to the strong activating methoxy group on the benzene ring. The mixture was poured into cold water and a yellow compound precipitated which was filtered in vacuum, dried over anhydrous calcium chloride. The solids obtained were recrystallized with $50 \mathrm{~mL}$ of $95 \%$ methanol giving a percentage yield of $77 \%$ and melts at $115^{\circ} \mathrm{C}$.<smiles>COc1cccc2cccnc12</smiles>

\section{Preparation of 5-Amino -8-Methoxyquinoline \\ Reduction Process}

$10 \mathrm{ml}$ concentrated hydrochloric acid was used to dissolved $0.050 \mathrm{~g}$ of 5-nitro-8methoxyquinoline and $1 \mathrm{~g}$ of tin dust was added with vigorous shaken. The mixture was heated on water bath for $1 \mathrm{hr}$ until all the nitro compound disappeared. The reaction mixture was subsided to about $30^{\circ} \mathrm{C}$ and $40 \mathrm{~mL}$ cold water was used to neutralize the medium. It was extracted with $40 \mathrm{ml}$ chloroform and a brownish solid was obtained which was further recrystallized and purified using column chromatography. The percentage yield obtained was $96 \%$, it melt at $142^{\circ} \mathrm{C}$ and $\mathrm{R}_{\mathrm{f}}$ of 0.86 using benzene and chloroform in ratio $3: 1$ as a mobile phase.

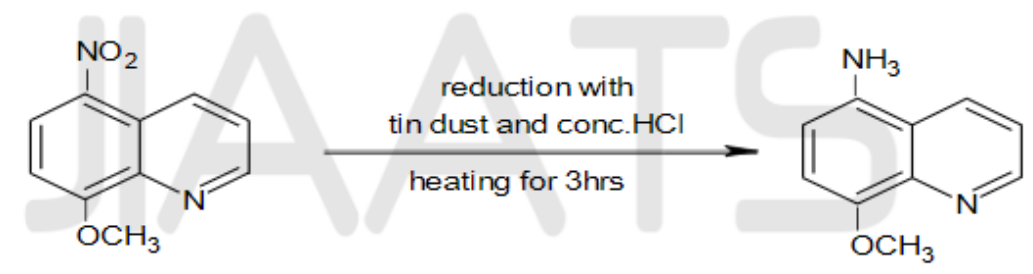

\section{Preparation of 8-Methoxy -5-Aminoacetic acid}

Into $100 \mathrm{~cm}^{3}$ flask, $20 \mathrm{~mL}$ of $5 \%$ sodium carbonate solution was used to dissolved $0.041 \mathrm{~g}$ of $5 \mathrm{amino-8}$ methoxyquinoline, $0.025 \mathrm{~g}$ of Monochloroacetic acid was coupled with mixture and the reaction medium was stirred for $3 \mathrm{hrs}$. At the end of the reaction, the medium was neutralized with $10 \mathrm{~cm}^{3}$ concentrated hydrochloric acid and a whitish 
solid precipitated. The precipitate was filtered, dried and recrystalized with $25 \mathrm{ml}$ of methanol. The percentage yield obtained was $60.97 \%$ and melt at $142^{\circ} \mathrm{C}$.<smiles>COc1ccc(NCC(=O)O)c2cccnc12</smiles>

\section{FT/IR Analysis:}

The IR of the compounds were recorded using spectroscopic techniques (Williams, 1993). These were done in University of Ibadan cenral research laboratory and University of New york, United kingdom. The model of the Infrared machine is spectrum Bruker Vortex 70 using Opus 2013 software, named as Ft-Ir system.

\section{Herbicidal Activity:}

For the herbicidal activity, $5 \mathrm{mg}$ of $\mathrm{Na}_{2} \mathrm{CO}_{3}$ was dissolved in $100 \mathrm{ml}$ of distilled water to give us $\mathrm{Na}_{2} \mathrm{CO}_{3}$ solution. $37 \mathrm{mg}$ of synthesized compound, 8-methoxy-5-amino acetic acid was dissolved in $\mathrm{Na}_{2} \mathrm{CO}_{3}$ solution. The solution was sprayed on the weeds using broadcast method (USDA Agricultural Research Service. 2010)

\section{Results:}

The FT/IR result is shown below.

Table 1 showing Absorption peak $\left(\mathrm{CM}^{-1}\right)$

\begin{tabular}{|c|c|c|c|c|c|}
\hline $\begin{array}{l}\text { FUNCTION } \\
\text { AL GROUP }\end{array}$ & $\begin{array}{l}\text { SPECTRUM } \\
\mathrm{A}\left(\mathrm{cm}^{-1}\right) \\
\end{array}$ & $\begin{array}{l}\text { SPECTRUM } \\
\mathrm{B}\left(\mathrm{cm}^{-1}\right)\end{array}$ & \begin{tabular}{|l} 
SPECTRUM \\
$\mathrm{C}\left(\mathrm{cm}^{-1}\right)$
\end{tabular} & $\begin{array}{l}\text { SPECTRUM } \\
\mathrm{D}\left(\mathrm{cm}^{-1}\right)\end{array}$ & $\begin{array}{l}\text { SPECTRUM } \\
\mathrm{E}\left(\mathrm{cm}^{-1}\right)\end{array}$ \\
\hline $\mathrm{O}-\mathrm{H}$ & 3447.00 & |--------------- & ---------------- & |----------------- & |-------------------- \\
\hline $\mathrm{C}=\mathrm{O}$ & & & --_-_-_-_-_- & - & 1614 \\
\hline $\mathrm{NO}_{2}$ & $\ldots \ldots \ldots$ & & 1338 & & \\
\hline $\begin{array}{l}\text { Aromatic } \\
\text { Absorption }\end{array}$ & $\begin{array}{l}3045.71,882.90- \\
481.08\end{array}$ & $\begin{array}{l}3049,892- \\
649\end{array}$ & $\begin{array}{l}2914, \quad 930- \\
620\end{array}$ & 1019,616 & $2453,889-655$ \\
\hline $\mathrm{N}-\mathrm{H}$ & 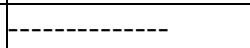 & --------------- & ------------- & 3348 & 3450 \\
\hline
\end{tabular}

SPECTRUM A : 8-HYDROXYQUINOLINE

SPECTRUM B : 8-METHOXYQUINOLINE

SPECTRUM C : 5-NITRO-8-METHOXYQUINOLINE

SPECTRUM D : 5-AMINO-8-METHOXYQUINOLINE

SPECTRUM E : 8-METHOXYQUINOLINE-5-AMINO ACETIC ACID

Spectra 1-5 shows the infra-red spectra of newly synthesized compound and its derivatives. 


\section{Spectrum1}
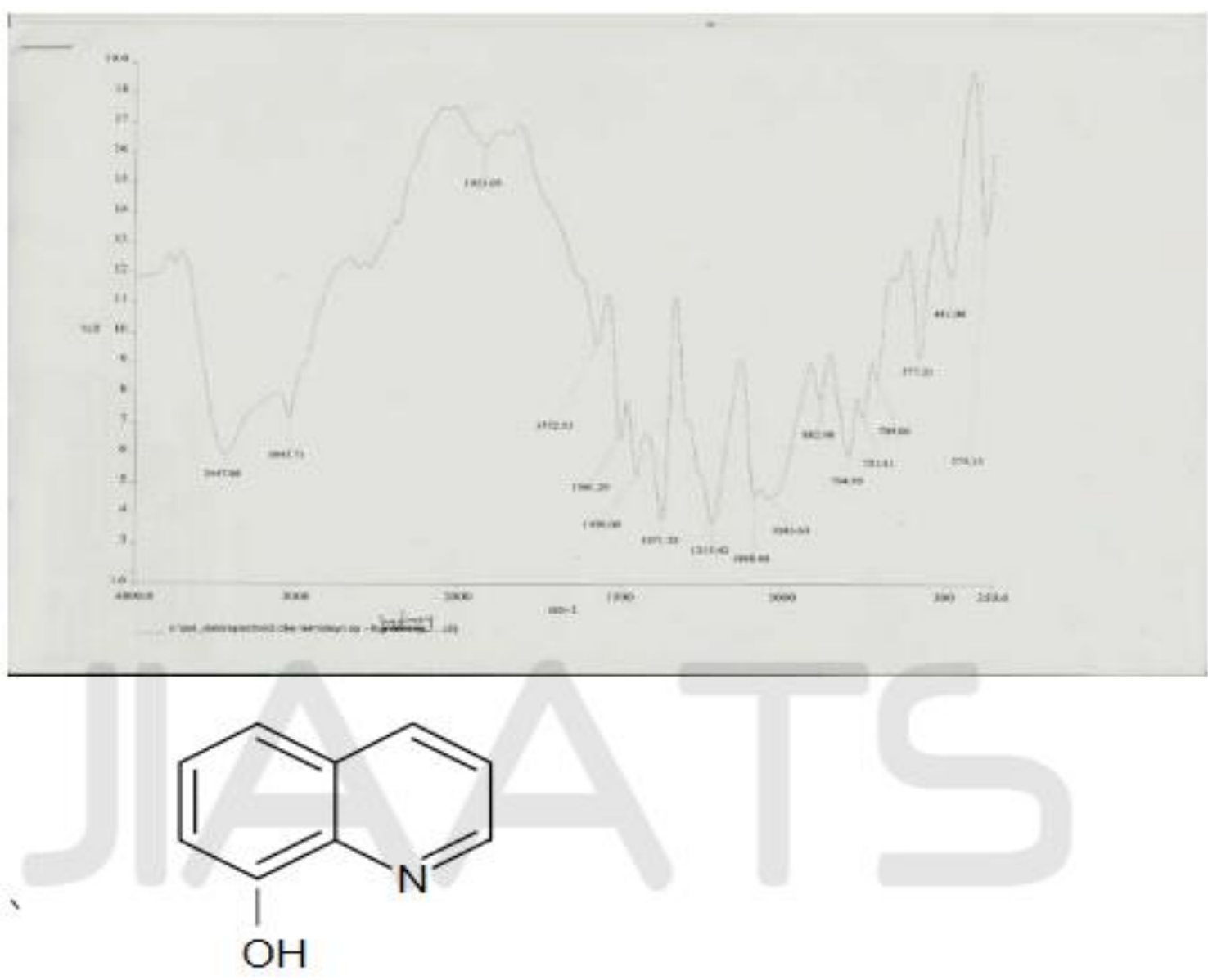

FIGURE 1: 8-HYDROXYQUINOLINE

\section{Spectrum 2}

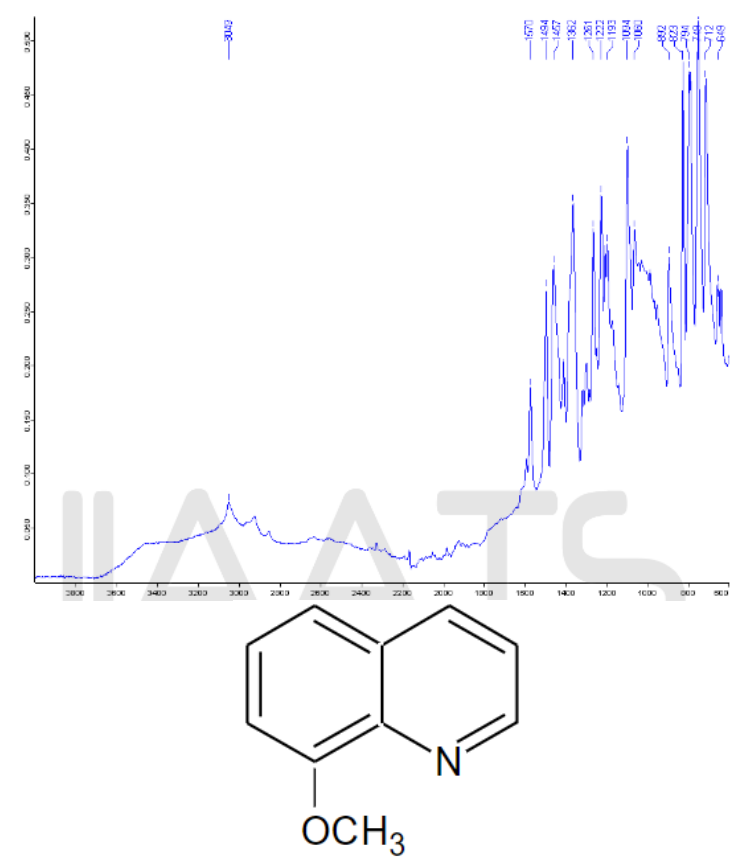

FIGURE 2:8-METHOXYQUINOLINE 


\section{Spectrum 3}

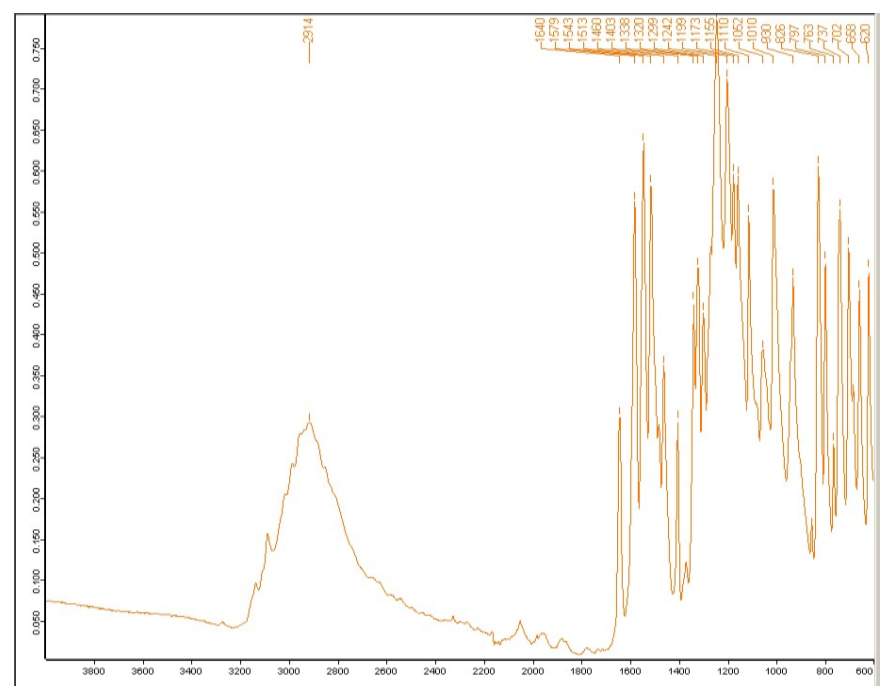<smiles>COc1ccc([N+](=O)[O-])c2cccnc12</smiles>

FIGURE 3: 5-NITRO-8-METHOXYQUINOLINE

Spectrum 4

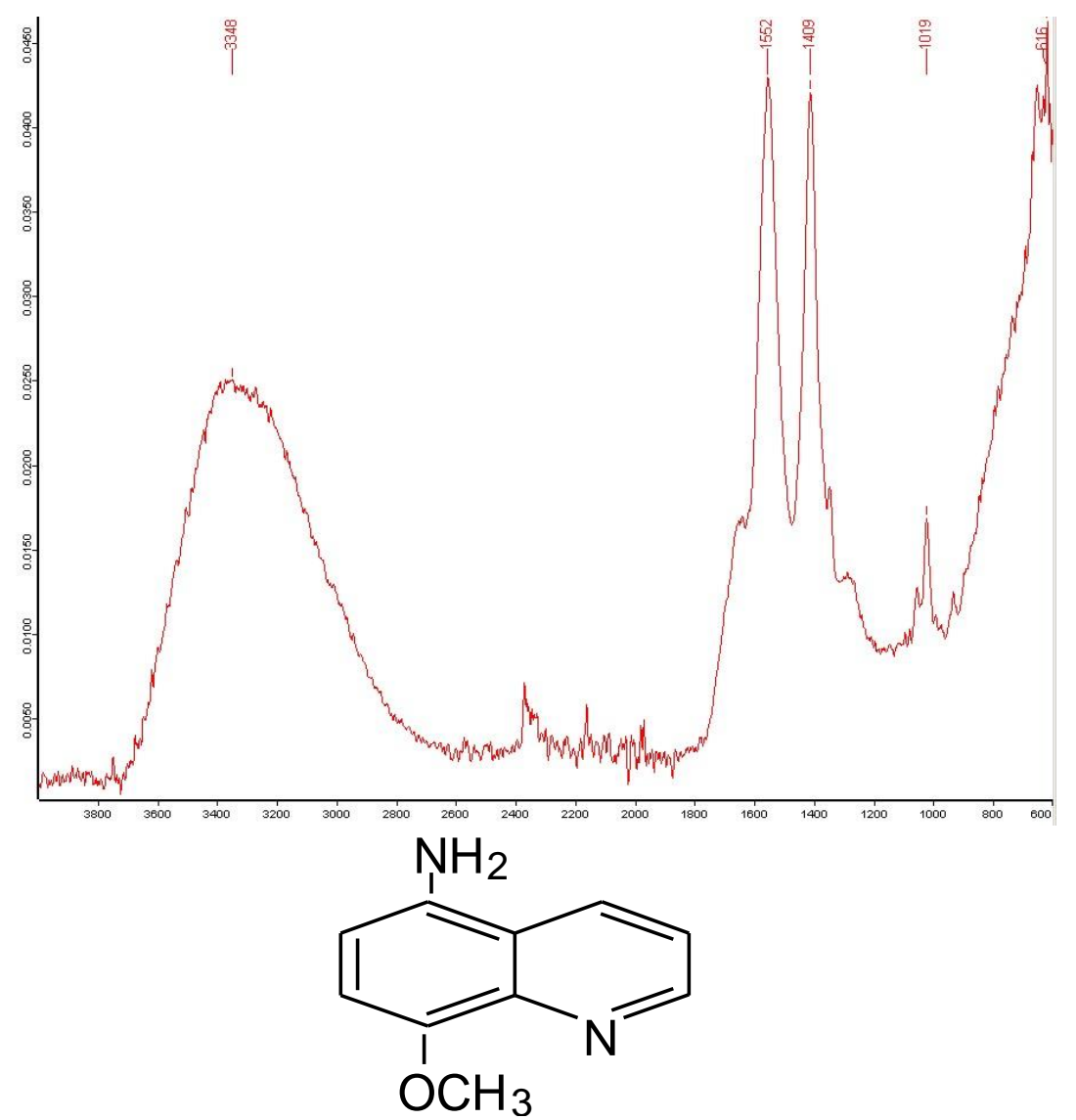

FIGURE 4: 5-AMINO-METHOXYQUINOLINE 


\section{Spectrum 5}
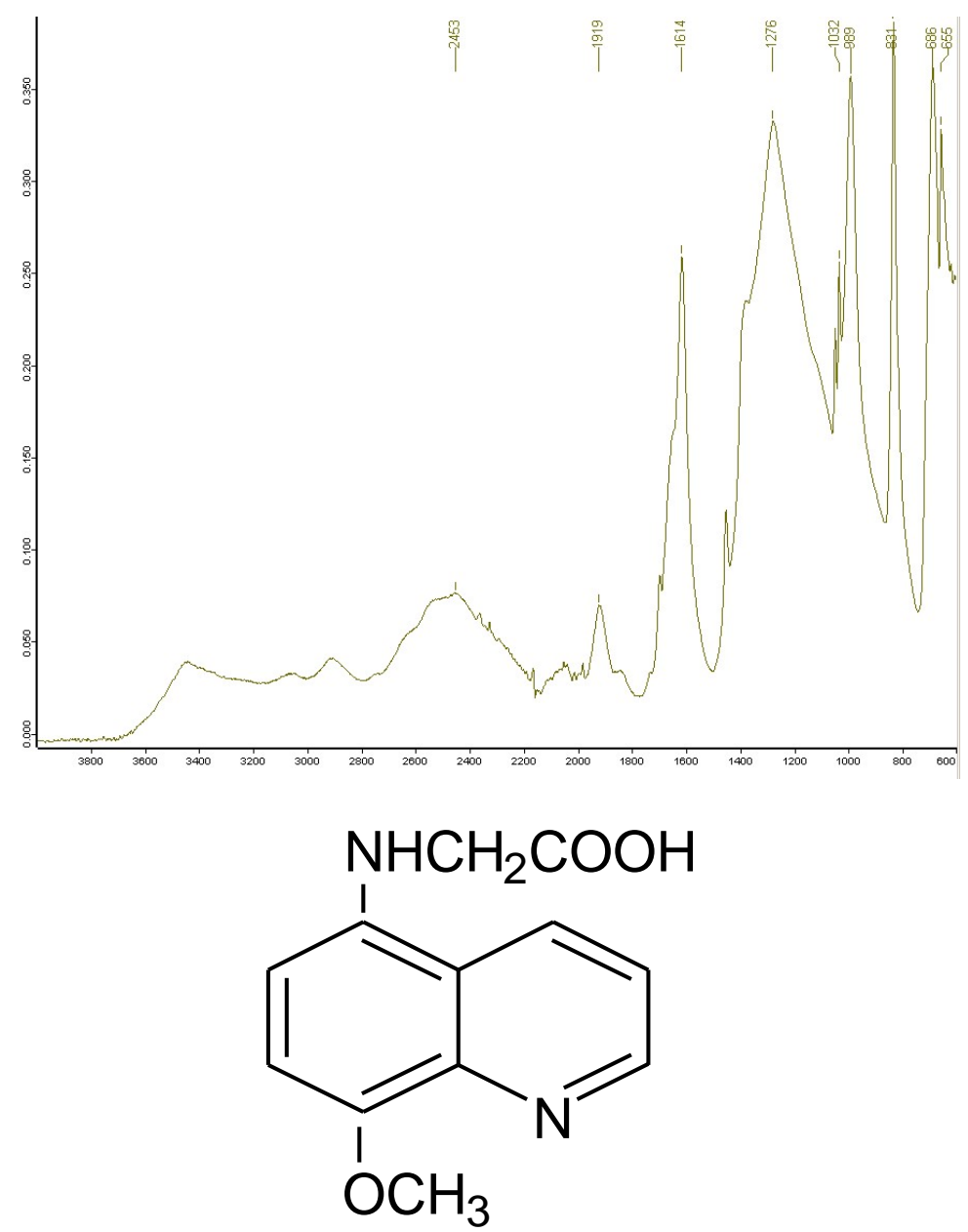

FIGURE 5: 8-METHOXY-5-AMINOACETIC ACID

Application of 8-methoxyquinoline-5-amino acetic acid on weeds;

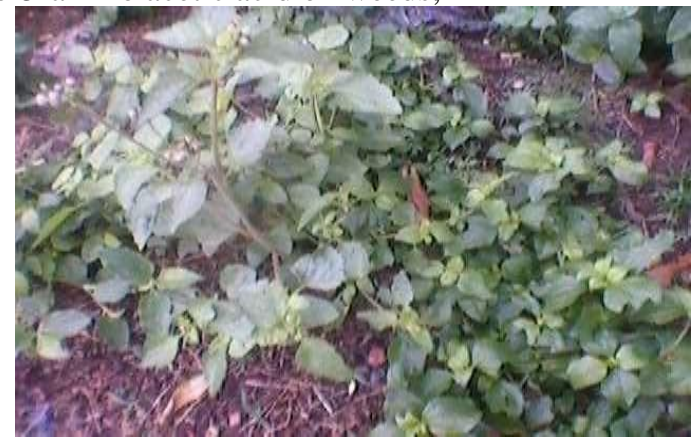

Effect after 11days of application;
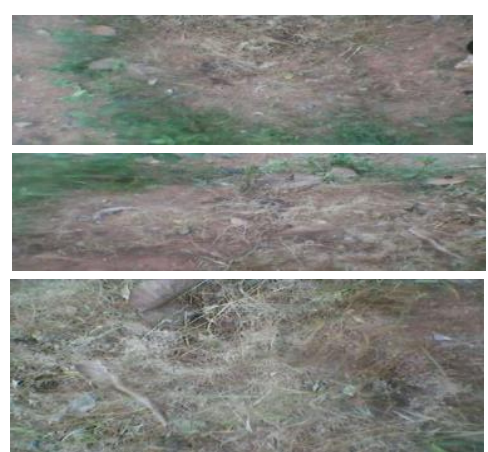

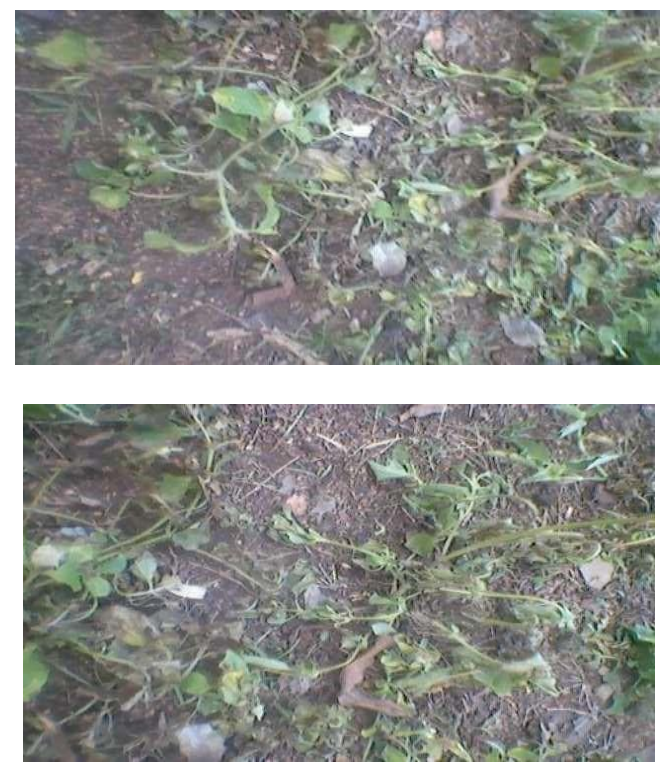

\section{Discussion}

The IR of figure 1 was run in the University of Ibadan, Nigeria while the IR of Figure 2 and 3 were run in the University of New York, London. From table 1, which showed the result of Infra red and figure1 showed the spectrum of 5hydroxyquinoline showing the functional groups present on the ring. Absorption at $3447.60 \mathrm{~cm}^{-1}$ depicts for $-\mathrm{OH}$, a $-\mathrm{CH}$ stretch absorption at $3045 \mathrm{~cm}^{-1}$, weak overtone with associated aromatic compound was seen at $1923 \mathrm{~cm}^{-1}, \mathrm{C}=\mathrm{C}$ stretch was seen at $1572 \mathrm{~cm}^{-1}$. In addition, from table 1 also and figure 2 showed spectrum of 8 -methoxyquinoline,the product form from reaction of 8hydroxyquinoline with methylodide with peak at $3049 \mathrm{~cm}^{-1}\left(-\mathrm{CH}\right.$ stretch), $\mathrm{C}=\mathrm{C}$ stretch $1570 \mathrm{~cm}^{-1}$, $-\mathrm{CH}$ bend in and out plane help in suggesting aromatic compound at $1094-712 \mathrm{~cm}^{1}$. Moreover, from table 1 which showed the IR and figure 3 showed spectrum of 5-nitro-8methoxyquinoline formed from the reaction of 8-methoxyquinoline with mixed acid (conc. Sulphuric and Nitric acid). Absorption at $2914 \mathrm{~cm}^{-1}$ depicts for $-\mathrm{CH}$ stretch, $1460 \mathrm{~cm}^{-1}$ for nitro group $(-\mathrm{NO})$, aromatic absorption $\mathrm{C}=\mathrm{C}$ stretch at $1579 \mathrm{~cm}^{-1}$ and other bonds like $-\mathrm{CH}$ bend in/out of plane on the fingerprint region help to suggest presence of aromatic ring at $1110-558 \mathrm{~cm}^{-1}$.

Figure 4 show spectrum of 5-amino-8-methoxyquinolie from the reduction of 5-nitro-8methoxyquinoline with tin dust and concentrated hydrochloric acid. Absorption at $3348 \mathrm{~cm}^{-1}$ amino group $\left(-\mathrm{NH}_{2}\right), \mathrm{C}=\mathrm{C}$ stretch at $1552 \mathrm{~cm}^{-1},-\mathrm{CH}$ bend at $1019-616 \mathrm{~cm}^{-1}$. Figure 5 show spectrum of 8-methoxyquinoline-5-amino acetic acid from coupling of monochloroacetic acid with 5-amino-8-methoxyquinoline. $-\mathrm{OH}$ stretch absorption and amino group $(-\mathrm{NH})$ which is not too prominent at $3450 \mathrm{~cm}^{-1}$ and $3300 \mathrm{~cm}^{-1}$, carbonyl $(\mathrm{C}=\mathrm{O})$ absorption depicts at $1614 \mathrm{~cm}^{-1}$ and $-\mathrm{CH}$ bend helps to show the presence of aromatic ring. An important characteristic feature which increases the likelihood of an aromatic compound present is the $\mathrm{C}-\mathrm{H}$ observed in the finger print region.

In addition, the compound, 8-methoxyquinoline-5 amino acetic acid exhibited strong herbicidal activities as shown in the pictures and proved effective as agro-chemical compound.

\section{Recommendation}

The synthesized compound still needs to be evaluated for its herbicidal activities using different concentration of the solution of the compound and also carry out laboratory investigation with other herbicides. Effect on plant crops needs to be investigated also.

\section{References}

[1].Andrew HC, John P, Reade (2011). Herbicides and Plant Physiology.John Wiley \& Sons.

[2].Cindy Hill (1987). garden guides.com

[3].Norman RO, Coxon J M (1993). Principles of Organic Synthesis. 3rd eds. Blackie

[4].Owolabi BJ, Olarinoye ON (2008). Organic Chemistry, Bohan press Ltd., Nigeria Pp.70-77.

[5].Quastel JH (1950). Agricultural Control Chemicals". Advances in Chemistry 1. p. 244.

[6].USDA Agricultural Research Service (2010). A New Way to Use Herbicides: To Sterilize, Not Kill Weeds.

[7].Williams K (1993). Organic Spectroscopy, 3rd Edition, Macmillan, Hong Kong p.285 